\title{
Competition Law for the Digital Era - An Adventurous Journey
}

\author{
Peter Georg Picht
}

Published online: 13 August 2019

(C) Max Planck Institute for Innovation and Competition, Munich 2019

The digital transformation challenges the established frameworks of our societies and economies, with competition law being no exception. Realizing - or sometimes rather assuming - that competition law needs to meet these challenges proactively, lawmakers, courts, agencies and scholars have taken up the task. To give only a few recent examples of topics and actions:

- The German Bundeskartellamt's Facebook decision testifies to the crucial role of data as a competition factor on digital markets.

- The booking, dating and searching platform sagas have been perpetuated of late by the Düsseldorf Higher Regional Court setting aside the ban on narrow bestprice clauses (enge Bestpreisklauseln); by the EU Commission fining Google $€ 1.49$ billion for abusive practices in online advertising; and by EU lawmakers agreeing on a new online platform regulation. No doubt, platform intermediaries, with their gatekeeping role (oftentimes horizontal as well as vertical), the strong network effects they can engender, and the difficulties their multi-sided business models pose to traditional market definition techniques, loom particularly large in a competition law for the digital era.

- The intense enforcement focus on Apple, reflected inter alia by (impending) investigations by both the EU Commission and the DOJ, as well as by the US Supreme Court's readiness to hear a customers' collective action case against the company, is due not least to the business model mega trend of creating digital ecosystems. The seamless integration of multifarious functionalities

Peter G. Picht is an affiliated Research Fellow at the Max Planck Institute for Innovation and Competition.

P. G. Picht ( $\square)$

Professor Dr., LL.M. (Yale); Chair for Economic Law, Chairman of Center for Intellectual Property and Competition Law (CIPCO), University of Zurich, Zurich, Switzerland

e-mail: peter.picht@rwi.uzh.ch 
presents many advantages to users, but also creates the potential for impacting market conduct in an anti-competitive manner.

- Although extensive, in-depth case law on anti-competitive interactions between algorithmic market tools still lies ahead, Eturas, Lufthansa, Topkins and similar cases, in combination with initial economic research on the worrying potential of algorithmic markets to arrive at equilibria of reduced competitiveness, foreshadow a protracted fight for protecting effective competition in this area.

- Negotiations and partly competition law-based litigation between mobility providers - in particular car manufacturers - and ICT patent holders appear as the concomitant of a digital transformation process which connects more traditional sectors to an ICT infrastructure, thereby increasing dynamic efficiency, enabling new market interactions, but also creating the potential for frictions in the competitive process, including hold-up or hold-out related to essential ICT patents.

The competition law(-related) toolbox for digital markets contains a broad range of (proposed) instruments. Not all of them are well-tried, some may remain mind games. Among these tools are drastic structural measures, such as breaking up the GAFA giants; an (almost) implemented, more-or-less sector-specific regulation, for instance the EU rules on digital platforms or geo-blocking; further-reaching regulatory proposals, such as an access regime for Connected Mobility data or a code of digital conduct to be implemented by all players holding a strategic market status; concepts at the intersection of competition law and other legal areas, e.g. GDPR data portability or competition law-based compulsory IP licenses; recommendations for revamping the pillars at the core of the competition law framework, such as traditional market power thresholds for intervention or the hitherto lenient approach towards tacit (algorithmic) collusion; and finally a set of more-or-less pioneering provisions in core competition law which allow, inter alia, for the definition of markets in which no money changes hands, for attributing market power to digital ecosystems based on a combination of network effects and lock-in, and for initiating merger control based on other criteria than turnover thresholds.

This tour d'horizon reveals that the application of competition law to digital matters presently is in an experimental stage - just as digital markets themselves. Unavoidable as this phase seems, there is a risk that careless fiddling about will harm the very goals and dynamics competition law was created to preserve. Among the aspects central to mitigating such perils are: (1) a well-delineated legal framework including ex ante and ex post components; (2) the involvement of stakeholders in benchmark building; and (3) a creative approach towards enforcement and remedies. Competition law is expanding not only its toolbox as mentioned above, but also its scope of being an important player in the ordering of ICT patent licensing and starting to play a similar role in data-related market practices.

At least part of the pertinent IP and data protection-related practices have been rightfully tackled as harmful to competition. Nonetheless, extending competition law in density and scope cannot be done at will without adverse effects regarding, for instance, legal certainty, resources required for compliance, or non-arbitrary 
enforcement priorities. In the future, we may therefore have to think about more self-enforcement in legal areas outside competition law, a more subsidiary role for case-by-case ex post competition law enforcement where other legal mechanisms prove apt to do the job, and an increase in coherent, though partially sector-specific ex ante regulation. As to the last point, the dynamics of digital transformation make the setting of ex ante rules for pro-competitive conduct particularly difficult. The involvement of stakeholders can help to develop, in a state-stakeholder interaction, such rules or at least benchmark principles. In a context of impending regulation, stakeholders have a vital interest to partake in this approach.

The risk of regulatory capture must be taken seriously, but it ought not to prevent cooperative exercises. Where ex ante benchmarks or the self-enforcement of other legal areas do not prevent anticompetitive outcomes, resort must be had to traditional antitrust remedies. In their present shape, however, these remedies may prove insufficient as well. Even very high fines may not worry the deep-pocketed leaders in digital economy. State-imposed product adaptations, such as the infamous Windows Media Player unbundling, can easily miss the mark of consumer preferences in fast-moving digital markets.

The attempt to empower customers by way of an abundance of information and consent requirements has largely proven a failure; data portability rights in their present form will, most probably, fare no better. Proposals to break up the GAFA giants are hallmarks for a potential end of the partial inertia of US antitrust enforcement, but those who criticize them as a combination of over-enforcement and helplessness do have a point.

All this shows that the design of appropriate, effective remedies is a very difficult task which requires greater attention and creative approaches, including longerrunning rather than of single-step measures, as well as a focus on self-evaluated, though controllable conduct adaptation instead of the realization of state-defined outcomes. At present, competition law is one of the pioneers in shaping the legal framework for our digital future. While taking all necessary freedom to experiment, its protagonists and stakeholders should assume responsibility for the coherence, the static as well as dynamic efficiency, and the welfare-enhancing potential of this framework as a whole.

Publisher's Note Springer Nature remains neutral with regard to jurisdictional claims in published maps and institutional affiliations. 